The Geneva Papers on Risk and Insurance, 14 (No. 53, October 1989), 347-359

\title{
Liability Rules and the Cost of Professional Indemnity Insurance
}

\author{
by Peter Cane*
}

Professional indemnity insurance (PII) basically protects the insured against the risk of incurring legal liability to pay compensation to clients or third parties. It follows from this that there must be some relationship between the cost of professional indemnity insurance and the content of the legal rules which regulate the potential liability of professionals. This can be demonstrated hypothetically by imagining a legal system in which some professional group enjoyed a complete immunity from legal liability to clients and third parties in respect of its professional activities. Members of such a group would have no incentive to purchase professional indemnity insurance. In the real world, insurance companies are not charities, and are unlikely to pay out under an indemnity policy, if a claim is litigated, unless the insured is held liable; or, if the claim is settled, unless it believes that the claimant has a strong case, ${ }^{1}$ or it sees some financial advantage in paying even though it believes that the claimant's case is weak. ${ }^{2}$ Some writers have attempted to explain certain aspects of the recent "crisis" in PII in Britain partly by reference to changes in the law affecting the liability of professionals (in particular for economic loss which have occurred in the last decade or so). ${ }^{3}$ Such an explanation is understandably appealing to lawyers interested in professional liability; it is also likely to appeal to insurers because it diverts attention away from factors over which they or their insureds may have some control onto an external scapegoat - the courts.

However, the nature of the actual relationship between liability rules and the cost of insurance is much harder to discern than the basic fact that there is a relationship. First, to take an example, advocates (whether barristers or solicitors) enjoy an immunity in English

\footnotetext{
* Corpus Christi College, Oxford. Thanks to the Geneva Association for funding the conference which caused me to think about the topic of this article.

${ }^{1}$ Even then, the amount paid out will be discounted to reflect the perceived risk that the plaintiff's claim might not have succeeded in whole or in part if the case had been tried.

2 For example, small claims have nuisance value. Such claims are perhaps likely to be more frequent against doctors than against some other professionals such as lawyers or accountants.

${ }^{3}$ See e.g. Lord Hacking, House of Lords Debates, Vol. 485, cols 1463-7. And see, generally Ougthon, Expanding Tort Liability in English Law and Compulsory Insurance for Professional Risks, (1989) Geneva Papers.
} 
law from liability in negligence in respect of "court work"; 4 nor can a barrister (as opposed to a solicitor) be sued by a "client" in contract because there is no contract between a barrister and the person he represents. However, the immunity only covers a part of the work of the advocate (in the case of barristers who specialize in certain types of work, and in the case of solicitors who also act as advocates, only a small part), and there would be no simple way of allowing for it in calculating the premiums to be paid by individual lawyers. Moreover, the fact of the immunity has not prevented premiums for both solicitors' and barristers' indemnity insurance rising very fast in recent years, nor has it prevented the Bar setting up a mutual insurance scheme or the Law Society withdrawing its block insurance scheme from the commercial market.

Secondly, even assuming that the scope of liability is "quantifiable" in such a way that it, or changes in it, can be fed into insurance premiums in some fairly precise way, and even assuming that this is done by insurers (points I shall return to later), the scope of liability is only one of the factors which affect premiums. Just as important as the "breadth" of liability rules is the likely willingness (assessed by extrapolation from past experience) of potential claimants to invoke the rules by making claims against professionals, and the likely number of claims (however assessed) against the particular insured. While both the number and the size of likely claims are partly a function of liability rules, they also depend on non-legal factors such as the type and quality of the services provided by the professional. Other factors relevant to the calculation of premiums are the size of the insured's business, the limits of indemnity selected, the cost of legal services used in defending and settling claims, the amount of investment income which the insurer can generate, the cost of reinsurance, and the insurer's need to make a profit. ${ }^{5}$

Thirdly, the situation is made even more complicated by the fact that the relationship between indemnity insurance and legal liability is arguably symbiotic: while changes in liability rules might trigger rises or falls in premiums, the availability of insurance might itself be thought to encourage extensions of liability; and, conversely, sharp increases in insurance premiums might be seen as a partial explanation for legal decisions restricting the scope of professional liability. In Britain all such possible effects must be largely matters for speculation because judges are, on the whole, extremely coy about the extra-legal motivations of their decisions, and insurers have an obvious commercial interest in attributing premium increases to external factors.

Given that the question of the relationship between liability rules and the cost of insurance is a complex one, how might the nature of the relationship be explored? There are obvious methodological problems: for example, lack of concrete evidence about the premium-fixing practices of insurers; lack of evidence as to the legal basis of the vast majority of (settled) claims; the impossibility of assessing the relative contribution to premiums of the various factors which affect rates, or at least of doing so in any but the most impressionistic way. However, some people have been willing to assume causal connections between some recent changes in liability rules of English law and recent dramatic increases

\footnotetext{
${ }^{4}$ Saif Ali v. Mitchell \& Co. [1980] AC 198. The exact scope of the immunity is unclear.

${ }^{5}$ This last factor is itself complex: insurers may cross-subsidize between different classes of business and even between different countries.
} 
in PII premiums. At first sight, such assumptions have an air of plausibility because the relevant changes in liability rules have, in theory at least, considerably increased the potential liabilities of some professional groups.

So I will examine the case for asserting such causal links in some detail. My argument will be threefold; first, that the changes that have taken place in liability rules in the last decade could not, in their own right, have justified more than very modest increases in PII premiums; secondly, that there are a number of other factors which are much more likely to have precipitated the large premium increases seen in recent years; and, thirdly, that there are, anyway, certain structural features of the situation which render implausible any argument which depends on an assumption that liability rules have a fairly direct and discernible effect on the cost of insurance - their effect is, on the contrary, likely to be indirect and somewhat mysterious.

It should be noted that the changes in the law which I will be discussing have occurred in cases involving liability for financial loss, and the following discussion is concerned primarily with purely economic loss, that is, economic loss which is not consequential upon injury or damage to the plaintiff's person or property (other than, in the case of defective buildings or chattels, the defective item itself); although I will occasionally make explicit mention of professional liability for personal injury. The reason for this concentration on economic loss is not that liability insurance costs paid by professionals, such as doctors, whose liability is primarily for personal injury, have not risen sharply in recent years: on the contrary, there is also a medical liability insurance "crisis". The reason is that the most significant changes in the rules of tort liability in recent years have related primarily to economic loss, and the argument I wish to explore is one which asserts a correlation between changes in liability rules and changes in insurance costs. This limitation of focus creates a further complication: some professional groups might incur liability either for purely economic loss or for personal injury or property damage (and consequential economic loss). But PII premiums paid by such professionals are most unlikely to reflect the fact that different rules govern liability for different types of loss. This makes the task of tracing the effects on premiums of changes in the law relating to purely economic loss even more difficult.

\section{Changes in liability rules}

It is necessary only to give a brief account of the relevant changes in liability rules.

\section{Duty of care}

In English law a defendant can be liable in the tort of negligence (the tort most relevant to professional liability) only if he is held to have owed a duty of care to the plaintiff. The determinants of whether a duty of care exists are sufficiently vague and flexible that the duty of care device can be used either to widen or to narrow liability for negligent conduct to conform with judicial views of desirable social policy. Two leading House of Lords decisions, one in $1970^{6}$ and the other in $1978^{7}$ ushered in an expansionary phase in the use of the duty concept. It was under the influence of this expansionary mood that it was held,

\footnotetext{
${ }^{6}$ Home Office v. Dorset Yacht Co. Ltd [1970] AC 1004

${ }^{7}$ Anns v. Merton London Borough Council [1978] AC 728
} 
for example, that a solicitor was liable to a disappointed beneficiary for failing to ensure that a will was properly executed. ${ }^{8}$ However, by the mid-1980's this trend had been largely reversed, and the House of Lords currently takes a quite restrictive attitude to liability for economic loss in tort (the expansionary mood had no discernible effect on the liability of professionals, such as doctors, for personal injury).

This general oscillation in the use of the duty concept is unlikely, in itself, to have had much impact on PII premiums. Its effects were not limited to professional liability claims as normally understood; and its exact impact on such claims is very difficult to assess in general terms. The most that can be said is that the expansionary cases might have generated an atmosphere of apprehension which may have exerted upward pressure on premiums; also, such cases may have contributed to a greater general awareness of the possibility of suing professional advisers, although it is a matter for speculation which was the chicken and which the egg. If the argument of causal link is to have any significant force it must be based upon the specific changes in professional liability rules which came about during the expansionary era.

\section{Concurrent liability in tort and contract}

In English law there is no general rule that the existence of a contract between $\mathrm{A}$ and $B$ precludes an action in tort by $A$ against $B$ in respect of facts which could give rise to an action based on the contract. ${ }^{9}$ But certain professional groups did at one time enjoy an immunity from suits in the tort of negligence brought by their clients. However, this immunity was explicitly removed in the case of solicitors,,$^{10}$ and there were grounds for saying that it had been entirely expunged from the law. ${ }^{11}$ The present position is unclear, ${ }^{12}$ but assuming that there is no rule against concurrent liability (as was generally assumed in the early 1980's) it is hard to assess the extent to which concurrent liability increases the potential liability of those professionals who could not previously be sued concurrently. There are dicta which suggest that a defendant could not be held to owe a duty in tort to his client wider than any duty owed in contract. ${ }^{13}$ It is also clear that any duty owed in tort would be subject to any effective limitations or qualifications of liability contained in the contract. The relevant rules of assessment of damages for negligence are likely in most cases to be the same in contract and tort.

An allegedly important difference between tort and contract lies in the area of limitation periods for non-personal injury actions. The limitation period in contract is six years from the date of breach, whereas in tort it is six years from the date the damage (whatever

\footnotetext{
${ }^{8}$ Ross v. Caunters [1980] Ch 297.

${ }^{9}$ But there are ambiguous dicta in Tai Hing Cotton Mill Ltd v. Liu Chong Hing Rank Ltd [1986]
} A.C. 80 .

10 Midland Rank Trust Co. v. Hett, Stubbs \& Kemp [1979] Ch 384

${ }^{11}$ See generally Cane "Contract, Tort and Economic Loss" in Furmston (ed.) The Law of Tort (London, 1986).

12 The dicta in the Tai Hing case referred to in note 9 could be interpreted to rule out concurrent liability or only to support the proposition that tort principles cannot be used to impose more onerous duties on the defendant than are imposed by his contract with the plaintiff.

${ }^{13}$ See previous note. 
this means in the particular case) occurs. In cases of latent damage, that is damage which is undiscoverable until some time after it occurs (whenever this happens), there is an alternative limitation period of three years from the date the damage becomes discoverable (the plaintiff can take advantage of whichever period expires later), subject to a longstop of 15 years from the date of the alleged negligence. ${ }^{14}$ It is not clear whether the rules about latent damage apply only to actions in tort or also to actions for negligence brought in contract. There are, thus, two respects in which limitation rules in tort may be more generous to the plaintiff than those in contract: in relation to "patent" damage, there may be a time gap between the allegedly negligent act and the occurrence of the damage; and in relation to latent damage, the plaintiff could have up to nine more years to bring an action in tort than in contract.

For present purposes, however, the rules about latent damage are not very important because they came into operation too recently ${ }^{15}$ to be able to explain the sharp premium increases in the early to mid 1980's. Before they came into effect, the same rules governed both patent and latent economic damage. In respect of the different starting dates of the limitation periods in tort and contract actions, it has been arguable, since 1982 anyway, that where the plaintiff's loss does not involve damage to person or property there will often be no significant gap between the date of the alleged negligence and the occurrence of the damage. ${ }^{16}$ For these two reasons, it is unlikely that the introduction of concurrent liability has had or will have more than a marginal effect on the number of successful claims made by clients against professionals.

Even less clear than the impact of the abolition of the rule against concurrent liability on the number of claims is its effect on premiums. It is worth noting incidentally that "premiums" charged by medical practitioners' mutual insurance unions have increased sharply in recent years (in one case, $87 \%$ in 1988). This has happened despite the fact doctors never enjoyed an immunity from concurrent liability in tort and contract ; and despite the fact that some doctors (hospital doctors employed by the National Health Service) can only be sued in tort because they have no contract with their patients. Furthermore, the rules governing the liability of doctors for personal injury and related losses, if they have changed at all, have become more advantageous to defendants in the last decade. Although any explanation of the PII crisis which purported to be valid for all professions would be suspect, the position of doctors at least suggests that powerful factors besides the legal basis of liability may have been at work in causing sharp increases in PII premiums. Part of the explanation, in the case of doctors, may be the fact that the component for medical expenses in personal injury awards has increased more than the rate of general inflation in recent years because the cost of medical services has increased more than the cost of many other commodities and services.

\section{Duties owed to third parties}

A number of cases in the late 1970's and early 1980's certainly did expand the potential liability of professionals for financial loss suffered by third parties. The possibility of

\footnotetext{
14 Latent Damage Act 1986.

15 September, 1986.

${ }^{16}$ Forster v. Outred [1982] 1 WLR 86; Moore v. Ferrier [1988] 1 WLR 267.
} 
liability to a third party for financial loss can be traced back to a case reported in $1964 ; ;^{17}$ the possibility became reality in cases which held a negligent solicitor liable to a disappointed beneficiary under a will, ${ }^{18}$ and a building society surveyor liable to the purchaser of the house. ${ }^{19}$ However, it is likely that these developments, too, were purely marginal to the problems of PII. The extension of liability to third parties potentially affects some professions much more than others - surveyors, accountants and auditors are perhaps the most vulnerable in this respect. But even in relation to these especially affected professions it is by no means clear how far the relevant developments actually extend liability. It has always been likely that English courts would refuse to impose liability in cases involving large numbers of potential plaintiffs on the basis of lack of a sufficiently close relationship of proximity between the defendant and the plaintiffs. More significantly, the PII crisis was not limited to the worst affected professions. Furthermore, it is likely that the large majority of claims made against professionals, even against those particularly subject to third party liability, are made by clients. Much apprehension, probably unnecessary, has no doubt been generated by a few well-publicised and very large third party claims against accountants, and this, rather than any objective assessment of the true meaning and impact of the cases on liability to third parties, may have exerted upward pressure on premiums.

\section{Liability for cost of repair}

The late 1970's saw the extension of liability in tort to cover the cost of repairing premises which were dangerous ${ }^{20}$ or, in some cases, just shoddy, ${ }^{21}$ even (perhaps) ${ }^{22}$ in the absence of any physical damage to the premises. This extension may well have increased the cost of PII to relevant professionals, but since the PII crisis was not limited to such professions, this extension cannot explain the crisis as it has affected other professions; and it is not clear to what extent it explains it even in relation to the effected professions. In light of the fact that the House of Lords appears very recently to have reversed these extensions of liability, ${ }^{23}$ it will be interesting to look for perceptible reductions in the insurance costs of relevant professions.

\section{Conclusion}

So although there have been significant changes in the rules governing professional liability in the last decade, it seems that they can (or at least should) have had no more than a marginal effect on the cost of insurance. Of course, the argument so far has assumed that there is a fairly direct relationship between liability rules and premiums, and also that the

\footnotetext{
${ }^{17}$ Hedley Ryrne \& Co. Ltd v. Heller \& Partners Ltd [1964] AC 465.

18 Ross v. Caunters [1980] Ch 297.

${ }^{19}$ Yianni v. Evans [1982] QB 43. 554.

${ }^{20}$ Anns v. Merton LBC [1978] AC 728; Batty v. Metropolitan Property Realisations Ltd [1978] QB

${ }^{21}$ Junior Books Ltd v. Veitchi Ltd [1983] AC 520.

${ }^{22}$ But see Pirelli General Cable Works Ltd v. Oscar Faber \& Partners [1983] 2 AC 1; see generally Stapleton "The gist of Negligence" (1988) 195 Law Q rev 213.

${ }^{23}$ D. \& F. Estates Ltd v. Church Commissioners for England (1988) (as yet unreported).
} 
content of the rules is capable of being accurately known and is in fact understood by insurers. I will discuss these assumptions later.

A final point to make at this stage is that whatever the impact of these changes in legal rules, they must be seen against the background of the main bulk of liability rules which have not changed. In particular, the most important issue in most professional liability claims is that of standard of care - was the defendant negligent? The basic approach of the courts to this issue has not changed in the last decade: the yardstick of due care is whether a responsible body of professionals would have acted as the defendant did; and although the courts are, in theory, willing to hold accepted professional practice to be negligent, they are unlikely to do so except in extreme circumstances. English courts are generally wary of imposing external standards of conduct on professionals - they see the issue of good practice as essentially a technical one, not an evaluative one concerned with the degree of care which society is entitled to expect of professionals or one concerned with the socially desirable allocation of risks of loss. The generally pro-defendant approach of the courts to the standard of care issue further reinforces the conclusion that liability rules have very little force in explaining the large premium increases, the reductions of cover and the contraction in the PII market wich have characterized the 1980's.

\section{Other possibly relevant factors ${ }^{24}$}

To what, then, is the 1980's PII crisis to be attributed? A number of possible factors have been sugested.

1. There seems to have developed recently a considerably heightened claims consciousness amongst the consumers of commercial and professional services. This is reflected in the development of arbitration schemes as an alternative to litigation and in the creation of ombudsmen and other complaints procedures in recent years - these can be seen as attempts by the professions to meet a groving demand for dispute resolution. In particular, one suspects that commercial consumers of professional services are now much less prepared than hitherto to leave their affairs to the professional and to put it down to experience if things go wrong. This may be the result partly of the general adverse changes in the economic climate in the 1970's and 1980's. At the same time, some professions, at least, (solicitors, for example) have become much more business oriented than they used to be. This is reflected, for example, in pressure to relax rules on advertising 25 and in proposals for multidisciplinary law practices. Many smaller firms are feeling the pressure of competition

${ }^{24}$ In this section I have relied heavily on: D. G. Davies "Professional Indemnity Insurance: The Current Crisis" [1985] PN 169; G. N. Reid "Professional Indemnity Insurance - An Insurers' View" [1986] PN 10; D.C. M. Blackburn "Professional Indemnity - a crisis of cover and capacity" [1987] PN 11; N. D. Hooker \& L. M. Pryor "Professional Indemnity Insurance" (unpublished paper delivered to a conference of actuaries in 1987).

25 In relation to personal injury, it is worth noting the Accident Legal Advice Scheme in which 3,000 solicitors' firms in England and Wales participate: under this scheme solicitors offer a free initial interview to accident victims to help them assess whether they have a claim worth pursuing. There is evidence that this scheme has led to successful claims being made by people who would not otherwise have made a claim. The potential of such initiatives for increasing the number of claims and, possibly, the level of premiums not only in the personal injury area but elsewhere too, is clear. 
following the abolition of the solicitors' conveyancing (that is, property transfer) monopoly; while large commercial firms now see themselves more as producers of a quality product at an appropriate price than, in the older style, as providers of a community service.

Such new attitudes may, in turn, have helped to change attitudes to professional services, stripping them of mystique and causing defective professional services to be viewed more like any other defective product. This increasing commercialisation of the professions and growing consumer claims consciousness may well have contributed to the much increased level of claims on PII policies. Certainly, the increased willingness of clients to make claims against professional advisers is likely to have been at least as important as the liability rules themselves in affecting the cost of insurance. It may be, too, that a few large well-publicised claims have had a disproportionate impact on insurance premiums by generating fear of a rash of very large claims and settlements.

2. In the late 1970 's and early 1980 's when interest rates were very high, premium income generated considerable investment income. This enabled and encouraged insurers to engage in severe competition by cutting premiums to uneconomic levels and increasing policy cover. When interest rates fell considerably, premiums had to be increased sharply and cover reduced to make up for the consequential loss of non-premium income. The explanatory force of this factor is, however, weakened when one considers that increases in premiums for PI policies have been very much larger than for other types of policy, whereas changes in interest rates affect income from investment of all premium income. Furthermore, the impact of falls in interest rates could be partially offset by shifting to different investments such as shares.

3. The demand for PII has increased enormously in recent years. For some professions PII is compulsory, ${ }^{26}$ while for other professions increased claims consciousness on the part of clients and other affected parties has increased the need for effective PII cover. Further, the explosive growth in the financial services and information services industries must have increased demand for insurance to cover liability for economic loss. Capacity in the PI insurance and reinsurance market is relatively limited, ${ }^{27}$ and this lack of capacity in the face of increased demand may partly account for the reduced cover, increased deductibles, limits on aggregate cover and increased co-insurance which have been features of the PII crisis. Stronger competition and greater capacity in the industry, had it existed, might have served to curb such developments to some extent. The fact that some insurers withdrew from the PII market entirely in the face of bad experiences in the early 1980's exacerbated the undercapacity.

4. The features of retrospective cover (a function of the claims-made nature of PII cover) and the long-tailed nature of PII are said to make it unattractive to insurers, and this also may have served to inhibit expansion of the market. (Claims-made policies protect against liability arising out of claims made during the period of the policy in respect of events which occurred at any time previously [subject to any cut-off date in the policy], whereas policies written on an "occurrence" or "activity" basis protect against liability arising out of claims in respect of events which occur during the period of the policy.) The main problem of the

${ }^{26}$ Liability insurance is not compulsory by law for any profession but several professional associations (eg the Law Society) require the purchase of some indemnity insurance as a condition of licensing.

${ }_{27}$ But for a contrary view see Lord Kimball HL Deb, Vol 485, col 1481. 
long tail - that is, the period, often long, between claim and settlement or judgment, is that liability rules may change adversely to the insurer in the meantime. But this is a problem common to all liability insurance. Further, the insurer writing insurance on an "occurrence" or "activity" basis has the additional problem that the time between the fixing of the premium and the notification of the claim will sometimes (notably in cases of latent damage) be very much greater than the equivalent period under a claims-made policy.

The problem generated by retrospectivity appears to be that the insurer will have less information about the past activities of the insured than about his present activities. Thus, the problem will be greatest when the insured has been in practice for some time but is a new or relatively recent customer of the particular insurer. The insurer writing insurance on an occurrence basis will, in the nature of the case, always be assessing risks inherent in current activities. However, this argument is a strong one only if it is assumed that insurers who are in a position to do so actually acquire detailed information relevant to the assessment of risks and subject it to careful actuarial analysis ; but, outside the area of life insurance, the validity of this assumption must be doubted. If such information gathering and analysis were the norm then experience rating would be much more developed than it appears to be. So it may be that the problem of retrospectivity is exaggerated.

5. It is more difficult for insurers to specify and monitor the execution of suitable risk management programmes in the case of PII than in respect of some other classes of business such as fire or theft insurance. One particular problem is the lack of reliable industry-wide information about the most common causes of PII claims. However, these problems are not peculiar to professional liability insurance but are more or less common to all forms of liability insurance.

6. It has often been argued that the large increases in "premiums" paid by doctors, whose liability is primarily for personal injury, are partly a result of the fact that maximum awards in personal injury cases have become very large in recent years, and that awards generally have increased more than the general rate of inflation. It is not clear whether an analogous argument could be made in relation to claims for economic loss. On the one hand, awards for non-pecuniary loss, a significant element in personal injury awards, are probably quite rare in economic loss cases and, even when made, quite small. On the other hand, property values and building costs have also risen ahead of the general rate of inflation in recent years; and this will have affected awards against some professional groups. Also, the fact that very large sums are at stake in many commercial deals with which professionals, such as accountants and solicitors, become involved, plus a number of recent, well-publicised and very large claims against accountants, may well have exerted upward pressure on premiums. However, this last argument should be treated with caution because it is often also argued that adequate indemnity cover for very large transactions is difficult, if not impossible, to obtain, and that many professional go without insurance in respect of the "upper layers" of their potential liability. To the extent that this is so, upward pressure on premiums cannot easily be attributed to the levels of cover being provided, but must be attributable to some other factor or factors - for example, increased frequency of claims within the band of readily available cover.

7. Another factor often mentioned as contributing to increased premiums is the cost of legal services and the fact that successful defendants cannot normally recover their costs from a legally aided plaintiff. However, neither of these factors is peculiar to cases involving 
economic loss or to cases against professionals, and the latter is of more importance to personal injury claims than in relation to economic loss claims since a proportion of plaintiffs seeking damages for economic loss will not be individuals. (The availability of legal aid is sometimes cited as an explanation for increasing numbers of personal injury claims, but the force of the argument is unclear).

8. Finally, the rule that each of a number of jointly and severally liable defendants is liable to the plaintiff for the whole of his damages award affects some professions, notably architects, particularly badly because their right of contribution against other tortfeasors, often builders, is frequently worthless because the builder is incorporated, and so enjoys limited liability, or has already gone into liquidation before the date of judgment. Also, architects who are employed by local authorities are said to be in a bad position because local authorities force on them very disadvantageous contracts. Whatever the force of these arguments, they could, at most, only explain why indemnity insurance for architects is expensive. These factors cannot by themselves even explain why architects' premiums have risen very sharply in recent years since these factors are not of recent origin.

\section{Conclusion}

It is clear that some of the above factors lack significant explanatory force. The most convincing explanations appear to be increasing claims consciousness and the relative lack of capacity and competition in the PII market. Problems of undercapacity in the market may be further exacerbated by the developing trend for professionals to withdraw from the private insurance market in favour of forming "captive insurers", ${ }^{28}$ setting up mutuals or even of "going bare". Some mutuals are profession-wide - e.g. those covering barristers and solicitors. Others are of limited scope, set up by groups of firms which presumably consider that they are low risks and that they can save money by withdrawing from the primary insurance market. The practice of going bare affects not only professions where liability insurance is not compulsory, but also professions where the limits of compulsory cover are relatively low (e.g. £ 500,000 in the case of solicitors). Profession-wide mutuals threaten capacity by removing large amounts of business from commercial insurers, thus potentially threatening the viability of some of them in respect of this line of business. Limited mutuals and self-insurance threaten it by removing from the market low-risk insureds, leaving traditional insurers with a pool of risks containing a disproportionate number of high risk insureds. ${ }^{29}$ This will tend to raise premiums even further and, in the extreme, lead to even further reductions of supply. The formation of captive insurers can have either effect.

Some argue that the worst of the PII crisis is over, at least in the sense that premium increases are generally slowing down and there has been some increase in capacity in the market. Assuming this to be so, and consistently with the argument so far, I doubt that this can be adequately explained by changes in liability rules. The new, more restrictive approach to duty of care is too recent and too unclear in its exact meaning and impact to have had any significant effect. The better explanation is perhaps simply that the financial

${ }^{28}$ See Madge Professional Liability Today Nov., 1986, pp. 6, 8.

${ }^{29}$ G. L. Priest "The Current Insurance Crisis and Modern Tort Law" (1987) 96 Yale LJ 1521. Much of the argument in this article does not, however, seem relevant to the PII crisis in Britain 
upheavals of the early 1980's have subsided; premiums have reached a new higher plateau, and insurers have developed techniques for limiting their exposure to manageable proportions - larger deductibles, limits on aggregate cover, and more co-insurance. Professionals, too, are actively exploring techniques - exclusions and limitations of liability, disclaimers, incorporation - to limit their exposure to claims of negligence. It may, however, be (ironically) the case that moves by professionals to limit their exposure might exacerbate their insurance problems by increasing consumer awareness of the possibility of claims and generate more, although perhaps lower, claims.

\section{Structural features}

I have assumed so far that liability rules have a fairly direct effect on premiums, and I have tried to assess the probable effect of recent changes in liability rules on the level of PII premiums. There are, however, good reasons to challenge the assumption that there is any direct or simple relationship between liability rules and premiums. For such an assumption to be justified, it would at least be necessary that the content and application of relevant liability rules were clear and certain. In fact the law as to professional liability for economic loss has been extremely uncertain in the last decade; and it may even be that uncertainty about the precise meaning and impact of changes in the law has, by generating fear and apprehension, exerted greater upward pressure on premiums than the changes themselves. The insurance market reacts particularly adversely to uncertainty because of the large element of prediction involved in setting premiums. But even in areas where the law has changed little, if at all, in the last decade - the liability of medical practitioners, for example - the concept of negligence is itself so vague and flexible that it introduces a large element of uncertainty into the operation of the law. ${ }^{30}$

It can be argued, therefore, that fear generated by change in the law may be more important than change itself in explaining increases in PII premiums. ${ }^{31}$ It may further be suggested that professionals and their organizations tend to exacerbate the problem of fear by a propensity to interpret changes in the law as having very adverse and undesirable consequences for themselves and their members. This can be seen as part of a continuing propaganda programme designed to bolster the privileged position of the professions in society by suggesting (implausibly) that the imposition of "excessive" legal liability will encourage "defensive practice" on the part of professionals; and that this will, in the long run, cause harm to the consumers of professional services by increasing their cost and suppressing professional "creativity". 32 Nor is the "fear factor" important only in under-

30 There is a widespread perception, which is false in my view, that any mistake made by a professional will be treated as negligence by the courts rather in the way that all mistakes by drivers tend to be treated as negligence. Cases cited in support of this observation are quite recent ones, which suggests that the perception is relatively recent one, and it might be part of the explanation for recent premium increases. The observation gives rise to spurious discussions about whether professionals ought to be put in a privileged position in respect of the standard of care required of them as a way of relieving pressure in insurance premiums.

31 Cf. K.S. Abraham (1987) 38 Ohio St L J 399,405-6. Conversely, it may be that complacency about the likely frequency and size of claims encouraged the setting of unrealistically low premiums earlier in the 1980's.

32 Besides being implausible, the argument is also circular because defensive practices would be unlikely to become incorporated into the legal duty of care if they were not widely adopted; it is also at odds with the argument that the equation of mistakes with negligence puts upward pressure on premiums because defensive practices are designed to reduce the risk of being held liable. 
standing the impact of (changes in) liability rules on premiums. I suggested earlier that a few, well-publicised large claims can generate a degree of fear disproportionate to their true predictive value. If I am right in stressing the importance of the "fear factor", this should make us wary of accepting without reservation any explanation of changes in PII premiums which assumes that insurers always act rationally in fixing premiums.

The fear factor would be much less potent if PI insurers regularly received and acted upon high quality and dispassionate advice as to the meaning and likely impact of changes in the law. Whether they do or not is, of course, an empirical question; but given the fact, for example, that outside the area of life insurance, actuarial skills appear to be little used in the fixing of insurance premiums, there is little reason to think that "scientific principles" are brought to bear on the question of the impact of liability rules on premiums. Indeed, two actuaries have recently written (in connection with PII) that, "[i]t is not easy to explain or predict the trends in claim frequency and severity. This is an area where the actuary will need to apply judgement". ${ }^{33}$ This view must arise partly as a result of the lack of reliable, industry-wide, data about the frequency, size and basis of professional negligence claims. This does not mean, of course, that insurers know nothing about the types of claim which are most likely to arise. For example, individual professionals might be able to negotiate a lower premium by excluding from the policy coverage types of claim which are well known to arise frequently. ${ }^{34}$ And insurers do know that some professions are more vulnerable than others. But, given that the market for PII is relatively small and given the diversity of professions and risks covered, detailed information which is statistically significant and reliable enough to justify meaningful adjustments of individual premiums must be hard to come by.

Another point worth considering is that most professional negligence claims are, no doubt, settled. It is clear in the area of personal injuries that the uncertainty of the law combined with structural imbalances between the parties in the settlement process mean that liability rules have only an indirect and indefinable effect on settlements. ${ }^{35}$ In the context of professional liability for economic loss, too, rules of liability are very uncertain; but since a proportion of claimants will be commercial concerns rather than private individuals, the bargaining process may not as often be as skewed by inequalities of position as it is in the personal injuries context. However, it must still be the case that liability rules are just one resource available to negotiating parties in the settlement process. And it is, after all, the sums which are actually paid out (most often as the result of settlements) rather than any hypothetical liability which a court might impose in accordance with relevant liability rules, which are likely to have the greater effect on the setting of premiums.

Finally, as previously noted, the nature of the relationship between liability rules and premiums is made even more complex by the fact that not only do court judgments given and settlements made under legal rules have an impact on the availability and cost of insurance, but also the availability and cost of insurance can have an impact on the legal rules.

${ }^{33}$ Hooker \& Pryor, op. cit. n 24 above. In private correspondence an underwriter has recently told me that "the majority" of insurers do not keep up with legal developments. I have also heard it said (by an insurers' legal adviser) that considerations of legal liability are significantly outweighed by other (non-legal) factors in the fixing of premiums.

${ }^{34}$ Peter Madge Professional Indemnity Insurance (London, 1968) pp. 103-4.

35 See generally Genn Hard Bargaining (Oxford, 1988). 
In the context of liability for personal injury, it is well recognized that it is only the availability (and sometimes the requirement) of liability insurance which makes the recovery of large awards of damages a possibility. It can also be said (perhaps more controversially) that fear of large increases in premiums has exerted a restraining influence in recent years on the level of awards. It would be surprising if a similar symbiotic relationship did not exist in the case of PII. The caution of the courts in imposing liability on professionals seems to be bred partly of a fear of "defensive practice", and also of forcing up insurance premiums. However, recognition of such a symbiotic relationship only makes matters more obscure given that, in this account, the availability of insurance pulls in one direction, while fear of premium increases pulls in the other, leaving the final upshot impossible to discern.

\section{Conclusion}

Examination both of recent relevant changes in the law governing the liability of professionals for economic loss and of the context in which PII premiums are fixed suggests that the relationship between liability rules and premiums is extremely complex and largely unfathomable. I have suggested some alernative explanations for the recent PII crisis, but it must be admitted that not all of these explanations carry great conviction. My conclusion is, therefore, negative and minimal, namely that the causes of the recent PII crisis remain to be fully explained. 